\title{
The updated Swiss guidelines 2016 for the treatment and follow-up of cutaneous melanoma
} \author{
von Moos ${ }^{g}$, Yousef Najafi ${ }^{h}$, Merlin Guckenberger ${ }^{h}$, Andreas Arnold ${ }^{i}$ \\ ${ }^{\text {a }}$ Skin Cancer Centre, Dept. of Dermatology, University Hospital of Zurich, Switzerland \\ ${ }^{\mathrm{b}}$ Dept. of Oncology, Kantonalspital St. Gallen, Switzerland \\ ${ }^{\mathrm{c}}$ Skin Cancer Centre, Dept. of Dermatology, University of Bern, Inselspital, Bern, Switzerland \\ ${ }^{d}$ Division of Plastic Surgery and Hand Surgery, University Hospital of Zurich, Switzerland \\ ${ }^{\mathrm{e}}$ Dept. of Oncology, University Hospital of Lausanne, Switzerland \\ ${ }^{f}$ Dept. of surgical Pathology, University Hospital of Zurich, Switzerland \\ ${ }^{9}$ Dept. of Oncology, Kantonalspital Chur, Switzerland \\ ${ }^{\mathrm{h}}$ Dept. Radiation Oncology, University Hospital of Zurich, Switzerland \\ ' Dept. of Dermatology, University Hospital of Basel, Switzerland
}

Reinhard Dummer ${ }^{a}$, Marco Siano $^{b}$, Robert E. Hunger ${ }^{c}$, Nicole Lindenblatt ${ }^{d}$, Ralph Braun ${ }^{a}$, Olivier Michielin ${ }^{e}$, Daniela Mihic-Probst ${ }^{f}$, Roger

\section{Summary}

Cutaneous melanoma is the most deadly cutaneous neoplasm. In order to guide treatment decisions and followup of melanoma patients, guidelines for the management of melanoma in Switzerland were inaugurated in 2001 and revised in 2006 and 2016. Recent data on surgical and medical treatments from randomised trials necessitated modification of the treatment and follow-up recommendations.

Key words: melanoma; guidelines; staging; therapy; follow-up

\section{Introduction}

The incidence of cutaneous melanoma is the highest in Europe and still rising. Melanoma is responsible for most deaths caused by skin malignancies. For these reasons, treatment guidelines have been published in 2001 and were revised in the versions of 2006 and 2011 [1,2], in order to provide reasonable practical recommendations for all physicians (general practitioners, dermatologists, surgeons, oncologists and others) who encounter cutaneous melanoma in their daily work [3]. The recommendations presented here have been graded according to the amount of scientific evidence supporting them using the "Level of Evidence" classification [4].

Levels of evidence:

IA Evidence from meta-analysis of randomised controlled trials

IB Evidence from at least one randomised controlled trial

IIA Evidence from at least one controlled study without randomisation
IIB Evidence from at least one other type of quasi-experimental study

III Evidence from nonexperimental descriptive studies, such as comparative studies, correlation studies and case-control studies

IV Evidence from expert committee reports or opinions or clinical experience of respected authorities, or both Grades of recommendations:

A Directly based on Level I evidence

B Directly based on Level II evidence or extrapolated recommendations from Level I evidence

C Directly based on Level III evidence or extrapolated recommendations from Level I or II evidence

D Directly based on Level IV evidence or extrapolated recommendations from Level I, II, or III evidence

The purpose of these updated guidelines is to ensure the adequate management and treatment of melanoma patients in Switzerland. Patients with low-risk melanoma still tend to be over-treated, whereas the therapy and follow-up procedures for patients with high-risk or metastasising melanoma are sometimes inadequate, especially if the patients are managed outside centres of excellence. Drawing on the combined expertise of a multidisciplinary team, the guidelines reflect current international standards and the state of the art [5]. Departure from these guidelines in special clinical situations is at the discretion of the individual physician.

There are several important differences between the Swiss recommendations and other recommendations:

1. Based on daily experience, the quality of the sentinel lymph node procedure (imaging, surgery and histological evaluation of the node) is sometimes poor in Switzerland. The guidelines therefore underline the necessity to refer patients with intermediate risk to specialised centres in order to assure adequate quality. 
2. The best population for adjuvant interferon therapy are patients with micrometastases and/or ulceration. Pegylated interferon-alpha $2 \mathrm{~b}$ injected weekly is preferred, based on its favourable pharmacology and its easier use for patients, and is approved in Switzerland.

3. New approaches such as immune checkpoint inhibitors and kinase inhibitors are approved first-line treatment options. In order to improve our knowledge further, clinical and translational research is essential. Therefore, patients should be referred to centres that are able to include patients in clinical trials and are fulfilling strict quality assurance.

4. Positron emission tomography (PET) / computed tomography (CT) scanning is covered by the Swiss health insurers for melanoma follow up. Its role is restricted to high-risk patients.

\section{Clinical melanoma subtypes [6]}

Superficial spreading melanoma (SSM) is the most common subtype (70\%) and is characterised by an initial flat phase that shows changes in size, shape or colour. SSM may occur in young adults but the mean age is in the 40 s. More than 100 melanocytic naevi and multiple dysplastic naevi are strong risk factors. SSM has been linked to intermittent ultraviolet (UV) light exposure and sunburns, especially in adolescence and childhood.

Nodular melanoma (NM) accounts for about $15 \%$ of melanomas overall, but for the majority of thick melanomas. It presents as a symmetrical, raised, firm, often uniformly coloured and frequently non-pigmented nodule that is rapidly enlarging and becoming more raised. Bleeding and crusting are common. NM occurs more often in older people, particularly men, and is more commonly seen on the head and neck than elsewhere.

SSM and NM often carry BRAF mutations.

Lentigo maligna (LM) and lentigo maligna melanoma (LMM, the invasive form of $L M$ ) account for $10-15 \%$ of melanomas. It has an initial flat phase that may be prolonged. It presents as an evolving pigmented macule and has to be differentiated from seborrhoeic keratoses, solar lentigines and pigmented actinic keratoses. LM has been linked epidemiologically to large cumulative doses of UV light, has a strong predilection for the head and neck, and is more common in outdoor workers, in older people and in association with solar damage and nonmelanoma skin cancer. Desmoplastic melanoma often arises in LMM.

Acral lentiginous melanoma (ALM) accounts for $1-3 \%$ of melanomas and occurs on the acral skin of the palms and soles including the nail apparatus. Importantly, melanomas that appear relatively flat on the soles of the feet may have significant depth histologically. Although the epidemiology is not as well understood, this type of melanoma is at least equally common in people with dark skin and has no relationship with UV exposure.

Rare variants of melanoma. There are other, rare variants of melanoma such as naevoid or acanthotic, amelanotic melanomas and mucosal (e.g., oral cavity, sinus, oesophagus, rectum, vulva/vagina, etc.) which represent together not more than $5 \%$ of all melanomas.

\section{Diagnosis of melanoma}

Skin examination for melanoma screening requires inspection of the entire body surface under good conditions (good lighting). Dermoscopy is a noninvasive technique with a hand-held magnifying device and immersion technique or polarised light in order to render the stratum corneum translucent. This technique allows the visualisation of diagnostic features of pigmented skin lesions that are not seen with the naked eye and has been shown to improve diagnostic accuracy significantly compared with naked eye examination in the hands of an experienced investigator (level of evidence Ia).

Lesions that are different from the patient's other lesions (ugly duckling lesions) [7], lesions that have a history of change (dynamic) or lesions with the dermoscopy criteria of severe atypia or malignancy should be excised.

Fast growth and ulceration are important features of thick melanomas including amelanotic melanoma.

Diagnosis should be based on a full thickness excisional biopsy with a small side margin. Processing by an experienced pathology institute is mandatory.

\section{Staging}

Physical examination with special attention to other suspicious pigmented lesions, tumour satellites, in-transit metastases, regional lymph node and systemic metastases is mandatory.

In low-risk melanomas (tumour thickness $<1 \mathrm{~mm}$ ) no other investigations are recommended. In higher stages imaging as suggested in the follow-up section is recommended in order to allow proper staging.

The improved version of the pTNM [8,9] system (table 1) is the classification system of choice.

\section{Therapy}

\section{Surgical treatment of localised primary melanoma}

Diagnosis should be based on a full thickness excisional biopsy. Suspicious melanocytic lesions should be excised completely, with a narrow clinical margin (level of evidence IV). The final diagnosis of melanoma is made histologically.

The histology report should follow the World Health Organization classification and include maximum thickness in millimetres (Breslow), presence of ulceration, determination of mitotic rate in tumours $<1 \mathrm{~mm}$, presence and extent of regression and clearance of the surgical margins [10]. The final surgical therapy should be carried out within 4 to 6 weeks following primary resection, leaving a safety margin of 1-2 cm, depending on the thickness of the tumour (table 2). Special locations, such as the face, may necessitate exceptions from the recommended safety margins but micrographically controlled surgery should be used. In these locations, radiotherapy might be considered as an alternative treatment option for lentigo maligna melanoma [11]. 


\section{Sentinel lymph node biopsy}

In the past decade, sentinel lymph node biopsy (SLNB) has become standard for staging cutaneous melanoma. The accuracy and reliability of the method, and the status of the sentinel lymph node (SLN) as the single most important prognostic factor for tumour recurrence and survival of melanoma patients has been proven beyond any reasonable doubt (level of evidence IV) [12]. SLNB does not improve overall survival [13]; however, there is general agreement that it will help identify patients who might benefit from further therapy, such as completion lymph node dissection (CLND) and adjuvant interferon therapy, and will allow their enrolment in adjuvant-therapy clinical trials [14]. SLNB should be discussed with and offered to all patients with primary melanoma of Breslow thickness equal to or greater than $1.0 \mathrm{~mm}$ and clinically normal regional lymph nodes (determined by physical examination and/or ultrasound). In patients with a thickness between 0.7 and 1.0 $\mathrm{mm}$, SLNB should be considered and discussed in healthy patients with additional risk factors such as enhanced proliferation or ulceration (pT1b) [15].
According to the current TNM classification and the UICC [9] (International Union Against Cancer, Issue 7), lymph node micrometastases have to be distinguished from isolated tumour cells. Isolated tumour cells are single tumour cells or small clusters of cells that are smaller than $0.2 \mathrm{~mm}$, can be detected with immunohistochemistry and are also visible with conventional stains. Isolated tumour cells do not have typical features of metastases such as proliferation or stromal reactions.

The pathology report for the SLNB should clearly distinguish between isolated tumour cells and metastases. Metastases are larger than $0.2 \mathrm{~mm}$ or, if smaller, show features such as sinus contact, stromal reaction or proliferation. It is essential to indicate the maximum diameter of the lymph node metastasis or extranodal involvement. In contrast to breast cancer, in melanoma SLNB micro- and macrometastases are not histopathological terms, but correspond to occult versus clinically apparent metastases. In order to provide high-quality histopathological assessments the histological diagnosis of melanoma should be confirmed by a reference pathologist for quality reassurance [16].

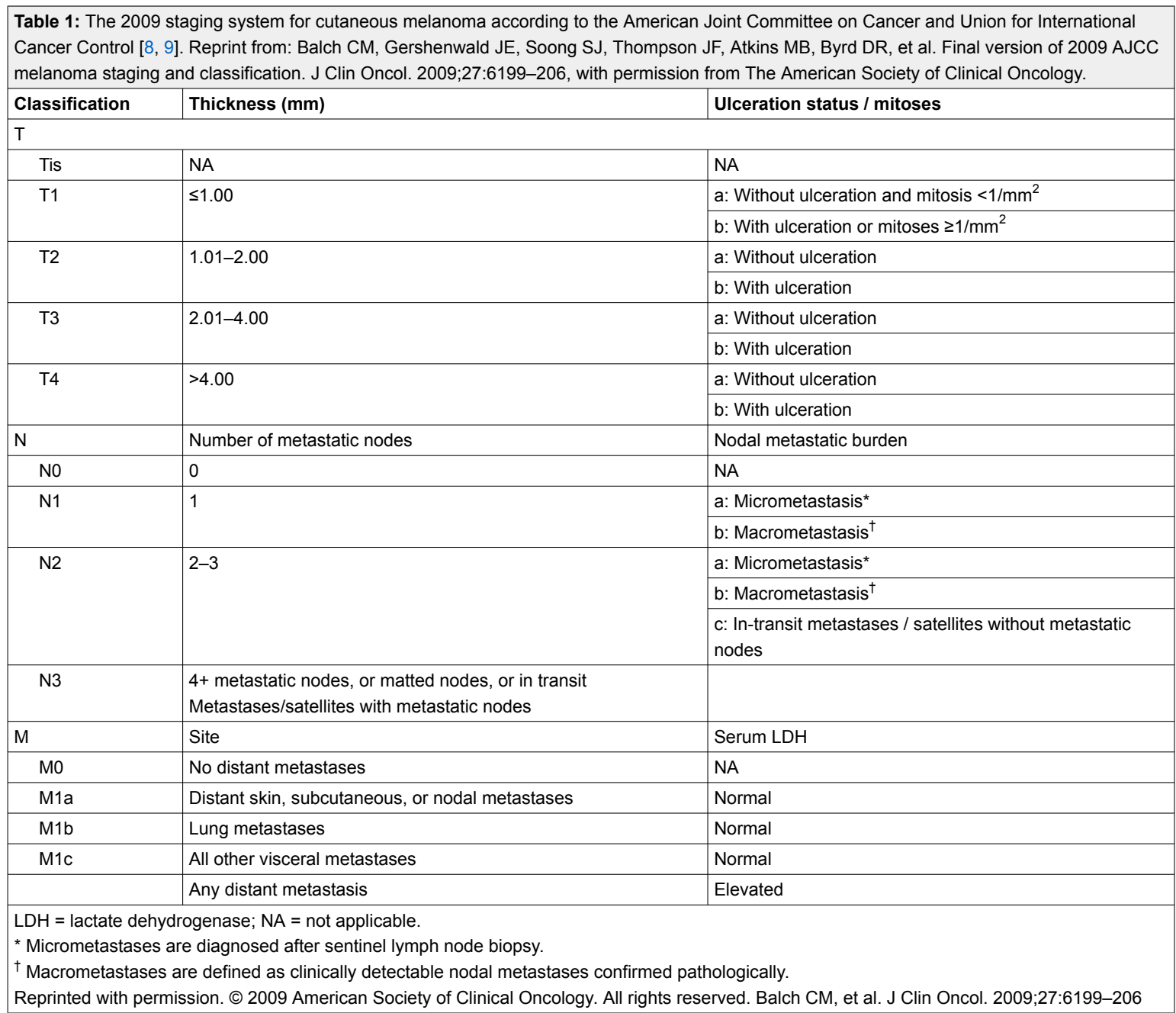

\begin{tabular}{|l|l|}
\hline Table 2: Excision safety margins (I, A) for surgical treatment of primary melanoma (pT1-4NxM0) [2]. \\
\hline Tumour thickness (Breslow) & Excision safety margin (cm) \\
\hline Melanoma in situ (tumour thickness is not indicated) (pTisN0M0) & 0.5 \\
\hline$<2 \mathrm{~mm}(\mathrm{pT} 1-2 \mathrm{NOM} 0)$ & 1 \\
\hline$>2 \mathrm{~mm}(\mathrm{pT} 3-4 \mathrm{NOM} 0)$ & 2 \\
\hline
\end{tabular}


The pathological investigation of the sentinel lymph node is difficult and should be performed in institutes of pathology with a high level of experience.

\section{Completion lymph node dissection}

Routine elective lymphadenectomy or irradiation to the regional lymph nodes is not recommended (II, B).

Following the introduction of SLNB as standard of care in the treatment regimen of cutaneous melanoma, completion lymph node dissection (CLND) was recommended, according to the Augsburg Consensus guidelines [17], for all patients with a positive SLNB. Thus, roughly $80 \%$ of all patients who were sentinel-negative were spared elective lymph node dissection. Whereas SLNB is a minimally invasive procedure with limited morbidity, CLND, much like extended lymph node dissection (ELND), is associated with considerable complication rates and socioeconomic costs [18]. Several studies reported an increased diseasefree survival with no significant impact on overall survival, raising the question as to whether lymph node dissection is necessary in the case of a positive SLNB. In a recent study, CLND reduced subsequent regional lymph node metastases and improved disease-free survival, while overall survival remained unaffected [19]. Sixty-seven to $90 \%$ of SLN-positive patients do not have further non-SLNs that contain tumour deposits in the CLND specimens [20]. As a consequence, the majority ( $80 \%$ ) of SLN-positive patients undergo unnecessary surgery associated with considerable morbidity. Therefore, several authors have tried to identify patient, tumour and SLN characteristics predicting further non-SLN positivity to safely avoid CLND [20]. Although previous studies have failed to identify the same clinicopathological features as indicators for additional non-SLN positivity upon CLND or for disease-free survival [21], SLN tumour load, nevertheless, was uniformly confirmed by all of these studies as prognosticator for non-SLN positivity and recurrence. In addition, the impact of SLN tumour burden on disease-free and overall survival was demonstrated in several studies [20]. CLND has not yet been proven to improve overall melanoma-specific survival. However, Cascinelli et al. [22] have shown that CLND is necessary to achieve the best assessment of prognosis of stage IB and II melanoma and to identify those patients who, having only positive sentinel nodes and negative non-sentinel nodes, have a good prognosis. There is considerable debate as to how to stratify SLN tumour burden; Satzger et al. [23] found that isolated tumour cells are without prognostic significance and disease-free survival of these patients did not differ from that of SLN-negative patients, an observation that is supported in a broader sense by Van Akkooi et al. [24]. In their study, no patient with an SLN tumour load of $<0.1 \mathrm{~mm}$ had additional non-SLN positivity upon CLND, and 5-year overall survival was $100 \%$. On the basis of these data, the UICC classifies SLNs with isolated tumour cells as negative ( $\mathrm{pNO}(\mathrm{i}+)$, in contrast to the AJCC, who define every melanoma cell, even if single, as a metastasis (pN1a). There is currently no consensus among eminent guidelines $[12,25]$ as to whether isolated tumour cells should be considered as metastases and the patient consequently undergo CLND or not. Therefore, we do not recommend complete lymph node dissection in pa- tients who present only isolated tumour cells in their sentinel node until the presence of this pathological feature has shown clear prognostic implications. Discrepancies exist in particular in the role of the SLN tumour burden and on the value of ultrasound-guided follow-up, a method that can detect early recurrences in the regional nodal basin and prompt a CLND only in patients with such evidence. Based on these differing expert opinions, the benefits and shortcomings of CLND should be discussed carefully with patients having SLN with isolated tumour cells and stage N1a with low tumour load, until the currently ongoing Multicenter Selective Lymphadenectomy Trial II has clarified these issues. Recurrences in the regional nodal bases, irrespective of whether it was previously staged or not, mandate lymph node dissection [26]. However, before undertaking additional aggressive local surgical treatments, a detailed staging investigation, including imaging techniques such as CT or PET, is necessary to exclude the presence of further metastases.

\section{Adjuvant therapy}

Many clinical trials have investigated the impact of adjuvant treatment modalities in high-risk melanoma. However, solid evidence can be gleaned only from prospective randomised multicentre trials. Neither ELND, perfusion of the extremities, radiotherapy or chemotherapy have been able to produce a significant increase in the length of survival rate benefit to the melanoma patient collective as a whole [27]. Adjuvant treatment with Viscum album (Iscador ${ }^{\circledR}$ ) is not recommended, since it might accelerate the disease course [28]. A large international trial using pegylated interferon has demonstrated a positive effect on disease-free and overall survival in patients with micrometastases and an ulcerated primary tumour (pTxb, N1a) $[29,30]$. In this patient population interferon can be recommended, if the individual patient tolerates it well (level of evidence III). Adjuvant treatment in patients with resected macroscopic involvement (N1b) should only be applied in the context of clinical trials in specialised centres.

Many new adjuvant trials including checkpoint inhibitors trials, are under development for patients with stage III disease and could soon extend to stage IIB and IIC patients (some of whom having a higher risk of developing metastatic disease than a subgroup of stage IIIA patients). We therefore recommend that, irrespective of their staging, all these patients should be referred to specialised centres in order to give them the chance of being enrolled in adjuvant therapy trials.

Radiotherapy for local tumour control should be considered in cases of inadequate resection margins of lentigo maligna melanoma [11] or R1 resections of melanoma metastases when surgery is not adaquate (III, B). A prospective randomised trial has demonstrated that postoperative irradiation after lymph node dissection reduces the risk for relapse in the irradiation field by approximately $50 \%$, but has no impact on relapse-free and overall survival [31].

\section{Local therapy of distant metastasis}

In the case of regional disease, surgery or radiotherapy may be an effective palliative treatment option, if it is technically feasible, if risk of morbidity and mortality is low and 
if the patient is likely to live long enough to derive a benefit. A PET-CT scan should be performed before any local treatment to exclude further lesions. Good examples for palliative surgery or radiotherapy are single lesions localised to the brain, bowel, liver and lung or spinal cord. In some patients a long survival time after complete resection has been described [32-35].

\section{Radiotherapy}

Radiotherapy plays an important role in achieving local control and palliation of many symptoms in melanoma patients, especially for symptomatic brain metastases, painful bone, lymph node and soft tissue metastases, as well as nerve compression symptoms. For extracranial metastases, irradiation with larger single-fraction doses is preferred and total doses should be adjusted to the patient's life expectancy. Overall, good palliation can be obtained in two thirds of the cases. Whereas whole brain irradiation is still the standard treatment for patients with multiple brain metastases and patients with short life expectancy because of progressive extracranial disease, stereotactic radiotherapy or radiosurgery alone without whole brain irradiation has become the standard for patients with a limited number of melanoma brain metastases [36].

Whereas radiotherapy alone or in combination with chemotherapy is well established, the combination with targeted drugs is an area of particular interest and data about potential interactions between radiotherapy and systemic treatment are still not mature. In patients with melanoma brain metastases, concurrent administration of ipilimumab and stereotactic radiosurgery or short-course fractionated stereotactic radiotherapy was safe [37, 38].

Administration of ipilimumab during or after radiotherapy may be beneficial in terms of overall survival and regional recurrence [39], but whether timing and sequencing of radiotherapy and ipilimumab influence toxicity and efficacy remains unclear The safety of combining radiotherapy in general or radiosurgery for brain metastases with inhibitors of B-RAF (serine/threonine-protein kinase B-RAF) is reported controversially in the literature and no data from prospective trials are available. Whereas some studies reported B-RAF inhibitors as radiosensitisers [40, 41] with the potential consequence of increased or severe toxicity, especially radiation recall dermatitis [33, 42], this was not confirmed by other studies [43, 44]. Nevertheless, it is generally recommended to stop B-Raf inhibitors during whole brain irradiation, but not stereotactic therapy; however, data confirming this practice are rare or even conflicting $[37,45]$.

\section{Systemic treatment of metastatic melanoma}

Since a few years ago, there is exciting progress in treatment of advanced recurrent and metastatic melanoma [46]. Guidelines can hardly keep up with standard practice-changing data presented and published. Nevertheless we believe that patients should be referred to interdisciplinary skin cancer centres that offer well-designed clinical trials whenever possible. Genetic testing for potential driver mutations with the prospect of treatments with targeted agents and small molecules such as B-Raf inhibitors, MEK inhibitors, phosphoinositide 3-kinase (PI3K) inhibitors and others are strongly recommended. The individual mutations profile is essential for treatment decisions.

Testing for BRAF mutation in exon 15 is required. In BRAF wild-type tumours N-RAS mutation testing in exons 1 and 2 should be considered. Both mutations are overwhelmingly mutually exclusive. N-RAS testing should be performed if participation in a clinical trial or a treatment with a MEK inhibitor in further treatment lines is planned. Testing for c-KIT mutation should be performed in acrolentiginous and mucosal melanoma in prospect of a clinical trial or treatment with a c-KIT inhibitor in the course of disease.

Unfortunately, clinical trials are not available for all melanoma patients. In this situation and in B-RAF, N-RAS, and c-KIT wildtype patients, systemic treatments with modern immunomodulatory checkpoint inhibitors are recommended (I, A). Classic chemotherapy agents, commonly used during past decades, have lost their importance in this disease.

The effectiveness of immunomodulatory agents is independent of the underlying genetic profile (before mentioned mutations) and no clinically useful predictive markers have been validated so far. This fact, together with the characteristic response patterns of delayed and long-lasting responses, renders the sequence of treatments, whether with small molecules or immunotherapy, one of the most important challenges for treating physicians.

Treatment sequence should be tailored to the patient and the individual medical needs (patient characteristics, tumour load, tumour dynamics, metastatic pattern, genetic profile). Treatment choice and sequence depends also on the local access to new agents through compassionate use or early access programmes and the approval status of agents considered by the Swiss regulatory authority.

\section{Immunomodulatory agents (checkpoint-inhibitors)}

The anti-CTLA4 (cytotoxic T lymphocyte-associated antigen-4) antibody ipilimumab was shown to prolong overall survival in first- and second- line therapy of stage IV melanoma $[47,48]$. Despite the considerable side effects, this treatment option is considered to be a reasonable firstor second-line therapy. Even in patients with naïve or pretreated brain metastasis, often underrepresented in large phase III trials, clinical benefit was demonstrated in phase II trials [Schadendorf JCO 2015]. This treatment should only be offered in specialised centres experienced in applying immunotherapies and in the treatment of related toxicities. It is recommended that the treating centres join national and international research programmes to contribute to a better understanding and definition of the patient population that profits from this therapy.

Anti-PD1 (programmed death-1) antibodies (pembrolizumab, nivolumab) show impressive results as first- and further line treatments, with impressive long-lasting responses and very promising survival rates $[49,50]$. The toxicity profile is more favourable than chemotherapy or ipilimumab with few grade 3 and 4 adverse reactions [49, 51]. Patients should be seriously considered for these agents within or outside of clinical trials.

The combination of ipilimumab and nivolumab shows promising response rates and progression-free survival in 
comparison with monotherapy, but its toxicity is significant [52]. Its impact on overall survival is not yet available and, therefore, it remains unclear if it is preferable to anti-PD1 monotherapy.

\section{Targeted therapy against driver mutations (B-Raf and others)}

Selective B-RAF inhibitors (dabrafenib, vemurafenib) have demonstrated high response rates and improved survival in comparison with chemotherapy in phase III trials for patients with BRAF mutations ( $40 \%$ of melanoma patients) $[53,54]$. Furthermore, combination treatments with B-RAF and MEK (mitogen-activated extracellular signal regulated kinase) inhibitors (dabrafenib with trametinib, vemurafenib with cobimetinib) improved response rates and survival, even lowering the incidence of specific toxicities (e.g. secondary skin tumours) in comparison with monotherapy [55-57].

In patients with BRAF-mutated symptomatic melanoma (pain, B symptoms, bulky disease) a B-RAF/MEK inhibitor combination represents a preferred therapy. There is no head-to-head comparison of this treatment with anti-PD1 therapy. The authors suggest the following aspects to apply to support first-line treatment with a B-Raf/MEK inhibitor combination:

- Patients with a symptomatic high tumour burden

- Patients with brain metastases, especially if

progressively symptomatic and if steroid treatment is needed

- Elevated lactate dehydrogenase levels, at least twice the upper limit of the reference range

- Patients with inflammatory syndrome with a shift in blood counts, neutropenia, and elevated C-reactive protein levels

- Evidence of bone marrow involvement

- Pre-existing autoimmune disease (rheumatoid arthritis, inflammatory bowel disease [Crohn's disease], Wegener's disease)

If clinical judgment, considering the criteria listed, suggests other therapies first, anti-PD1 immunotherapy should be considered as front-line treatment.

In patients with brain metastasis, promising intracranial efficacy has been demonstrated with B-Raf inhibitors [58, 59]. These new data established treatment algorithms and treatment modalities for patients with asymptomatic brain metastasis that suggest first-line palliative irradiation. Stereotactic irradiation can be safely combined with kinase inhibitors and is preferred to whole brain irradiation whenever feasible.

N-RAS-mutated melanomas should be considered for MEK inhibitor therapy in the course of treatment and cKIT-mutated tumours for treatment with tyrosinase kinase inhibitors despite the lower level of evidence and related studies on their way $[60,61]$.

\section{Cytotoxic chemotherapy}

With the emergence of novel targeted and immunotherapies, classic chemotherapy is losing its importance in this disease, as already mentioned. Nevertheless, in highly proliferating disease or as salvage treatment, chemotherapy can still be considered.
Dacarbazine (DTIC) is one of the most used substances in metastatic melanoma and is still the reference treatment in many countries. Temozolomide demonstrated efficacy equal to that of dacarbazine, but offers better penetration into the central nervous system. Treatment with bisphosphonates or denosumab should be considered in patients with bone metastases to avoid skeletal-related events and bone pain.

In aggressive symptomatic disease, polychemotherapy including cisplatin, vindesine and dacarbazine as first-line treatment (response rate: $40 \%$ ) [62] or the combination of carboplatin and paclitaxel as second-line [63] produced a partial response in $11 \%$ and disease stabilisation in $51 \%$ of the patients. However, an impact on disease-free or overall survival was not shown in either study.

Biochemotherapy, a combination of interleukin-2 and/or interferon-alpha with chemotherapeutic agents such as dacarbazine, temozolomide, fotemustine, cisplatin, carboplatin, vinblastine, paclitaxel or docetaxel demonstrated higher response rates but this was not translated into a better survival than that with a single agent, and has been associated whether an increase in toxicity $[64,65]$. It is not recommended. There are no randomised clinical trials of interleukin-2 monotherapy. Some centres still use this therapy in well-selected patients with low tumour burden, despite the lack of convincing phase III data.

Anti-vascular endothelial growth factor antibodies have shown some activity in phase II trials but no positive phase III studies have been reported so far [66, 67].

To conclude, all stage IV melanoma patients need to be referred to reference centres with broad experience in the management of this disease, discussed by an interdisciplinary melanoma tumour board and should preferably be treated in well-designed clinical trials. Recommended treatment strategies for metastatic melanoma are summarised in table 3 .

\section{Follow-up}

The patient should be instructed in avoidance of sunburn, extended unprotected solar or artificial ultraviolet exposure and in lifelong regular self-examination of the skin and peripheral lymph nodes. The patient must be aware that his or her family members have an increased melanoma risk.

The aim of melanoma follow-up is to detect a relapse or an additional skin tumour as early as possible. The risk of developing a second melanoma is $5-8 \%$ within the first 2 years after diagnosis. Thirty-five percent of patients with lentigo maligna melanoma develop another malignant tumour of the skin during the next 5 years [11]. Although the hypothesis suggesting that regular monitoring reveals early detection of metastasis may be well founded, no randomised studies have demonstrated that early detection of metastases improves the overall survival [68].

The follow up schedule is based mainly on dated literature and historical practice [69] (level of evidence IV). Despite numerous attempts to achieve international consensus on follow-up guidelines, there is no universal valid agreement. However, locoregional lymph node metastases are the most common event in patients that are regularly checked. Therefore, it is worthwhile to focus on cutaneous relapses 
and locoregional lymph nodes. Physical examination remains the mainstay of follow-up visits. In addition, patients should be trained in self-examination, because most relapses have been detected by themselves. This fact raises the question whether routinely performed clinical examinations and imaging procedures, based on the relapse risk over time, generate a real benefit for melanoma patients [27]. Probably false positive results could be reduced by increasing the time between visits and would anyhow be sufficient for psychological support [27].

The first 5 years after diagnosis are the most important, as $90 \%$ of all metastases occur during this period, and so clinical examinations and imaging procedures have to be more frequent for the first 5 years. Because melanoma is a tumour that can have late metastasis, lifelong surveillance beyond 10 years is generally recommended [70]. Thin melanomas with a Breslow depth less than $1 \mathrm{~mm}$ have only a small risk of relapse and thus need no imaging. Because sonography is easy to perform, cheap, not harmful and more sensitive than clinical examination in revealing lymph node metastasis, it should be routinely done. Table 4 presents the suggested time schedule of examinations for Switzerland. To detect further metastasis in stage III (and in stage IIC because of its similar prognosis) an imaging study of the whole body, preferably with PET-CT, is recommended [71]. S-100 protein is a good marker for melanoma relapse, especially for predicting disease-free survival in stage III melanomas [72, 73]. In stage IV melanomas intervals between check-ups have to be individually adjusted according the therapeutic intentions.

Disclosure statement: Prof. Dummer receives research funding from Novartis, Merck Sharp \& Dhome (MSD), BristolMyers Squibb (BMS), Roche, GlaxoSmithKline (GSK) and has a consultant or advisory board relationship with Novartis, Merck Sharp \& Dhome, Bristol-Myers Squibb, Roche,

GlaxoSmithKline, Amgen, outside the submitted work.

\begin{tabular}{|c|c|}
\hline Number and localisation of the metastases & $\begin{array}{l}\text { Treatment modalities } \\
\text { 1. } 1 \text { st choice } \\
\text { 2. 2nd choice } \\
\text { 3. 3rd choice }\end{array}$ \\
\hline In-transit metastases (few) (pTXN2cM0) & $\begin{array}{l}\text { 1. Surgical removal } \\
\text { 2. Radiotherapy }\end{array}$ \\
\hline Locoregional lymph nodes (pTxN1a,2a) & $\begin{array}{l}\text { 1. Consider trial participation } \\
\text { 2. Additional Interferon-alpha treatment* }\end{array}$ \\
\hline Solitary central nervous system metastasis ( $\mathrm{pT} \times \mathrm{N} \times \mathrm{M} 3$ ) & $\begin{array}{l}\text { 1. Neurosurgical removal } \\
\text { 2. Radiosurgery or stereotactic irradiation* (according to localisation this } \\
\text { could also be the } 1 \text { st choice) }\end{array}$ \\
\hline Solitary lung metastasis (pTxNxM1) & $\begin{array}{l}\text { 1. Surgical removal } \\
\text { 2. Stereotactic irradiation (SBRT) (according to localisation this could } \\
\text { also be the 1st choice) } \\
\text { 3. Consider clinical trial participation } \\
\text { 4. Targeted / immunotherapy* }\end{array}$ \\
\hline Multiple metastases (pTxNxM1a-1c) & $\begin{array}{l}\text { 1. Consider clinical trial participation } \\
\text { 2. Radiosurgery or stereotactic irradiation with up to } 5 \text { metastases } \\
\text { 3. Targeted/immunotherapy* }\end{array}$ \\
\hline
\end{tabular}

\begin{tabular}{|c|c|c|c|c|c|c|c|}
\hline $\begin{array}{l}\text { Stage } \\
\text { (TNM) }\end{array}$ & $\begin{array}{l}\text { Physical } \\
\text { examination } \\
\text { years 1-3 }\end{array}$ & $\begin{array}{l}\text { Physical } \\
\text { examination } \\
\text { years } 4-5\end{array}$ & $\begin{array}{l}\text { Physical } \\
\text { examination } \\
\text { years 6-10 }\end{array}$ & $\begin{array}{l}\text { Locoregional lymph } \\
\text { node sonography } \\
\text { years } 1-5\end{array}$ & $\begin{array}{l}S-100 \\
\text { years 1-5 }\end{array}$ & \begin{tabular}{|l|} 
Abdominal \\
sonography and \\
chest x-ray \\
years 1-5 \\
\end{tabular} & $\begin{array}{l}\text { CT, MRI, PET } \\
\text { or PET-CT } \\
\text { years 1-5 }\end{array}$ \\
\hline I ( $\leq \mathrm{T} 1 \mathrm{~N} 0)$ & 6-12 & 12 & 12 & - & - & - & - \\
\hline I (T2N0), IIA+B & 3 & 6 & $6-12$ & $6-12$ & $6-12$ & Individual & - \\
\hline IIC, III & 3 & 3 & 6 & 6 & 6 & Individual & $6-12$ \\
\hline IV & Individual & Individual & Individual & Individual & Individual & Individual & Individual \\
\hline
\end{tabular}


Correspondence: Reinhard Dummer, M.D., Dept. of

Dermatology, University Hospital of Zurich, Gloriastrasse 31, $\mathrm{CH}-8091$ Zürich, reinhard.dummer[at]usz.ch

\section{References}

1 Dummer R, Bosch U, Panizzon R, Bloch PH, Burg G. Swiss guidelines for the treatment and follow-up of cutaneous melanoma. Dermatology. 2001;203:75-80

2 Dummer R, Guggenheim M, Arnold AW, Braun R, von Moos R. Updated Swiss guidelines for the treatment and follow-up of cutaneous melanoma. Swiss Med Wkly. 2011;141:w13320.

3 Dummer R, Hauschild A, Lindenblatt N, Pentheroudakis G, Keilholz U. Cutaneous melanoma: ESMO clinical practice guidelines for diagnosis, treatment and follow-up. Ann Oncol. 2015;26(Suppl 5):v126-132.

4 Oxman AD, Sackett DL, Guyatt GH. Users' guides to the medical literature. I. How to get started. The evidence-based medicine working group. JAMA. 1993;270:2093-5.

5 Dummer R, Hauschild A, Guggenheim M, Keilholz U, Pentheroudakis G. Cutaneous melanoma: Esmo clinical practice guidelines for diagnosis, treatment and follow-up. Ann Oncol. 2012;23(Suppl 7):vii86-91.

6 Bastian BC. The molecular pathology of melanoma: An integrated taxonomy of melanocytic neoplasia. Annu Rev Pathol. 2014;9:239-71.

7 Grob JJ, Bonerandi JJ. The "ugly duckling" sign: Identification of the common characteristics of nevi in an individual as a basis for melanoma screening. Arch Dermatol. 1998;134:103-4.

8 Balch CM, Gershenwald JE, Soong SJ, Thompson JF, Atkins MB, Byrd DR, et al. Final version of 2009 AJCC melanoma staging and classification. J Clin Oncol. 2009;27:6199-206.

9 Webber C, Gospodarowicz M, Sobin LH, Wittekind C, Greene FL, Mason MD, et al. Improving the TNM classification: Findings from a 10-year continuous literature review. Int J Cancer. 2014;135:371-8.

10 Garbe C, Eigentler TK, Keilholz U, Hauschild A, Kirkwood JM. Systematic review of medical treatment in melanoma: Current status and future prospects. Oncologist. 2011;16:5-24.

11 Farshad A, Burg G, Panizzon R, Dummer R. A retrospective study of 150 patients with lentigo maligna and lentigo maligna melanoma and the efficacy of radiotherapy using grenz or soft x-rays. Br J Dermatol. 2002;146:1042-6.

12 Balch CM, Morton DL, Gershenwald JE, McMasters KM, Nieweg OE, Powell B, et al. Sentinel node biopsy and standard of care for melanoma. J Am Acad Dermatol. 2009;60:872-5.

13 Morton DL, Thompson JF, Cochran AJ, Mozzillo N, Nieweg OE, Roses DF, et al. Final trial report of sentinel-node biopsy versus nodal observation in melanoma. N Engl J Med. 2014;370:599-609.

14 Mocellin S, Pasquali S, Rossi CR, Nitti D. Interferon alpha adjuvant therapy in patients with high-risk melanoma: A systematic review and meta-analysis. J Natl Cancer Inst. 2010;102:493-501.

15 Han D, Zager JS, Shyr Y, Chen H, Berry LD, Iyengar S, et al. Clinicopathologic predictors of sentinel lymph node metastasis in thin melanoma. J Clin Oncol. 2013;31:4387-93.

16 Santillan AA, Messina JL, Marzban SS, Crespo G, Sondak VK, Zager JS. Pathology review of thin melanoma and melanoma in situ in a multidisciplinary melanoma clinic: Impact on treatment decisions. J Clin Oncol. 2010;28:481-6.

17 Cochran AJ, Balda BR, Starz H, Bachter D, Krag DN, Cruse CW, et al. The Augsburg consensus. Techniques of lymphatic mapping, sentinel lymphadenectomy, and completion lymphadenectomy in cutaneous malignancies. Cancer. 2000;89:236-41.

18 Guggenheim MM, Hug U, Jung FJ, Rousson V, Aust MC, Calcagni M, et al. Morbidity and recurrence after completion lymph node dissection following sentinel lymph node biopsy in cutaneous malignant melanoma. Ann Surg. 2008;247:687-93.

19 Leiter U, Buettner PG, Bohnenberger K, Eigentler T, Meier F, Moehrle $\mathrm{M}$, et al. Sentinel lymph node dissection in primary melanoma reduces subsequent regional lymph node metastasis as well as distant metastasis after nodal involvement. Ann Surg Oncol. 2010;17:129-37.
20 Guggenheim M, Dummer R, Jung FJ, Mihic-Probst D, Steinert H, Rousson $\mathrm{V}$, et al. The influence of sentinel lymph node tumour burden on additional lymph node involvement and disease-free survival in cutaneous melanoma - a retrospective analysis of 392 cases. Br J Cancer. 2008;98:1922-8.

21 Scolyer RA, Murali R, Gershenwald JE, Cochran AJ, Thompson JF. Clinical relevance of melanoma micrometastases in sentinel nodes: Too early to tell. Ann Oncol. 2007;18:806-8.

22 Cascinelli N, Bombardieri E, Bufalino R, Camerini T, Carbone A, Clemente $\mathrm{C}$, et al. Sentinel and nonsentinel node status in stage ib and i melanoma patients: Two-step prognostic indicators of survival. J Clin Oncol. 2006;24:4464-71.

23 Satzger I, Volker B, Meier A, Schenck F, Kapp A, Gutzmer R. Prognostic significance of isolated hmb45 or melan a positive cells in melanoma sentinel lymph nodes. Am J Surg Pathol. 2007;31:1175-80.

24 van Akkooi AC, Nowecki ZI, Voit C, Schafer-Hesterberg G, Michej W, de Wilt JH, et al. Sentinel node tumor burden according to the rotterdam criteria is the most important prognostic factor for survival in melanoma patients: A multicenter study in 388 patients with positive sentinel nodes. Ann Surg. 2008;248:949-55.

25 Garbe C, Peris K, Hauschild A, Saiag P, Middleton M, Spatz A, et al. Diagnosis and treatment of melanoma: European consensus-based interdisciplinary guideline. Eur J Cancer. 2010;46:270-83.

26 Morton DL, Wanek L, Nizze JA, Elashoff RM, Wong JH. Improved long-term survival after lymphadenectomy of melanoma metastatic to regional nodes. Analysis of prognostic factors in 1134 patients from the john wayne cancer clinic. Ann Surg. 1991;214:491-9; discussion 499-501.

27 Dummer R, Hauschild A, Guggenheim M, Jost L, Pentheroudakis G. Melanoma: ESMO clinical practice guidelines for diagnosis, treatment and follow-up. Ann Oncol. 2010;21(Suppl 5):v194-197.

28 Kleeberg UR, Suciu S, Broecker EB, Ruiter DJ, Chartier C, Liénard D, et al. Final results of the EORTC 18871/dkg 80-1 randomised phase iii trial: Rifn-alpha $2 \mathrm{~b}$ versus rifn-gamma versus iscador $\mathrm{m}$ versus observation after surgery in melanoma patients with either high-risk primary (thickness $>3 \mathrm{~mm}$ ) or regional lymph node metastasis. Eur J Cancer. 2004;40:390-402.

29 Eggermont AM, Suciu S, Testori A, Santinami M, Kruit WH, Marsden $\mathrm{J}$, et al. Long-term results of the randomized phase iii trial eortc 18991 of adjuvant therapy with pegylated interferon alfa- $2 \mathrm{~b}$ versus observation in resected stage iii melanoma. J Clin Oncol. 2012;30:3810-8.

30 Eggermont AM, Suciu S, Testori A, Kruit WH, Marsden J, Punt CJ, et al. Ulceration and stage are predictive of interferon efficacy in melanoma: Results of the phase iii adjuvant trials eortc 18952 and eortc 18991. Eur J Cancer. 2012;48:218-25.

31 Burmeister BH, Henderson MA, Ainslie J, Fisher R, Di Iulio J, Smithers BM, et al. Adjuvant radiotherapy versus observation alone for patients at risk of lymph-node field relapse after therapeutic lymphadenectomy for melanoma: A randomised trial. Lancet Oncol. 2012;13:589-97.

32 McLoughlin JM, Zager JS, Sondak VK, Berk LB. Treatment options for limited or symptomatic metastatic melanoma. Cancer Control. 2008;15:239-47.

33 Peuvrel L, Ruellan AL, Thillays F, Quereux G, Brocard A, Saint-Jean $\mathrm{M}$, et al. Severe radiotherapy-induced extracutaneous toxicity under vemurafenib. Eur J Dermatol. 2013;23:879-81.

34 Seegenschmiedt MH, Keilholz L, Altendorf-Hofmann A, Urban A, Schell H, Hohenberger W, Sauer R. Palliative radiotherapy for recurrent and metastatic malignant melanoma: Prognostic factors for tumor response and long-term outcome: A 20-year experience. Int J Radiat Oncol Biol Phys. 1999;44:607-18.

35 Rate WR, Solin LJ, Turrisi AT. Palliative radiotherapy for metastatic malignant melanoma: Brain metastases, bone metastases, and spinal cord compression. Int J Radiat Oncol Biol Phys. 1988;15:859-64.

36 Kocher M, Soffietti R, Abacioglu U, Villa S, Fauchon F, Baumert BG, et al. Adjuvant whole-brain radiotherapy versus observation after radiosurgery or surgical resection of one to three cerebral metastases: Results of the eortc 22952-26001 study. J Clin Oncol. 2011;29:134-41. 
37 Mathew M, Tam M, Ott PA, Pavlick AC, Rush SC, Donahue BR, et al. Ipilimumab in melanoma with limited brain metastases treated with stereotactic radiosurgery. Melanoma Res. 2013;23:191-5.

38 Tazi K, Hathaway A, Chiuzan C, Shirai K. Survival of melanoma patients with brain metastases treated with ipilimumab and stereotactic radiosurgery. Cancer Med. 2015;4:1-6.

39 Kiess AP, Wolchok JD, Barker CA, Postow MA, Tabar V, Huse JT, et al. Stereotactic radiosurgery for melanoma brain metastases in patients receiving ipilimumab: Safety profile and efficacy of combined treatment. Int J Radiat Oncol Biol Phys. 2015;92:368-75.

40 Hecht M, Zimmer L, Loquai C, Weishaupt C, Gutzmer R, Schuster B, et al. Radiosensitization by braf inhibitor therapy-mechanism and frequency of toxicity in melanoma patients. Ann Oncol. 2015;26:1238-44.

41 Ly D, Bagshaw HP, Anker CJ, Tward JD, Grossmann KF, Jensen RL, Shrieve DC. Local control after stereotactic radiosurgery for brain metastases in patients with melanoma with and without braf mutation and treatment. J Neurosurg. 2015:1-7.

42 Conen K, Mosna-Firlejczyk K, Rochlitz C, Wicki A, Itin P, Arnold AW, et al. Vemurafenib-induced radiation recall dermatitis: Case report and review of the literature. Dermatology. 2015;230:1-4.

43 Narayana A, Mathew M, Tam M, Kannan R, Madden KM, Golfinos JG, et al. Vemurafenib and radiation therapy in melanoma brain metastases. J Neurooncol. 2013;113:411-6.

44 Ahmed KA, Freilich JM, Sloot S, Figura N, Gibney GT, Weber JS, et al. Linac-based stereotactic radiosurgery to the brain with concurrent vemurafenib for melanoma metastases. J Neurooncol. 2015;122:121-6.

45 Gaudy-Marqueste C, Carron R, Delsanti C, Loundou A, Monestier S, Archier E, et al. On demand gamma-knife strategy can be safely combined with braf inhibitors for the treatment of melanoma brain metastases. Ann Oncol. 2014;25:2086-91.

46 Dummer R, Goldinger SM, Paulitschke V, Levesque MP. Curing advanced melanoma by 2025. Curr Opin Oncol. 2015;27:125-7.

47 Hodi FS, O'Day SJ, McDermott DF, Weber RW, Sosman JA, Haanen $\mathrm{JB}$, et al. Improved survival with ipilimumab in patients with metastatic melanoma. N Engl J Med. 2010;363:711-23.

48 Robert C, Thomas L, Bondarenko I, O’Day S, M DJ, Garbe C, et al. Ipilimumab plus dacarbazine for previously untreated metastatic melanoma. N Engl J Med. 2011;364:2517-26.

49 Ribas A, Puzanov I, Dummer R, Schadendorf D, Hamid O, Robert $\mathrm{C}$, et al. Pembrolizumab versus investigator-choice chemotherapy for ipilimumab-refractory melanoma (keynote-002): A randomised, controlled, phase 2 trial. Lancet Oncol. 2015.

50 Robert C, Long GV, Brady B, Dutriaux C, Maio M, Mortier L, et al. Nivolumab in previously untreated melanoma without braf mutation. $\mathrm{N}$ Engl J Med. 2015;372:320-30.

51 Weber JS, D'Angelo SP, Minor D, Hodi FS, Gutzmer R, Neyns B, et al. Nivolumab versus chemotherapy in patients with advanced melanoma who progressed after anti-ctla-4 treatment (checkmate 037): A randomised, controlled, open-label, phase 3 trial. Lancet Oncol. 2015; 16:375-84.

52 Larkin J, Chiarion-Sileni V, Gonzalez R, Grob JJ, Cowey CL, Lao $\mathrm{CD}$, et al. Combined nivolumab and ipilimumab or monotherapy in untreated melanoma. N Engl J Med. 2015.

53 Hausschild A, Grob JJ, Demidov LV, Jouary T, Gutzmer R, Millward $\mathrm{M}$, et al. Phase iii, randomized, open-label, multicenter trial (break-3) comparing the braf kinase inhibitor dabrafenib (gsk2118436) with dacarbazine (dtic) in patients with brafv600e-mutated melanoma. J Clin Oncol. 2012;30.

54 Chapman PB, Hauschild A, Robert C, Haanen JB, Ascierto P, Larkin J, et al. Improved survival with vemurafenib in melanoma with braf v600e mutation. N Engl J Med. 2011;364:2507-16.

55 Long GV, Stroyakovskiy D, Gogas H, Levchenko E, de Braud F, Larkin $\mathrm{J}$, et al. Combined braf and mek inhibition versus braf inhibition alone in melanoma. N Engl J Med. 2014;371:1877-88.

56 Larkin J, Ascierto PA, Dreno B, Atkinson V, Liszkay G, Maio M, et al. Combined vemurafenib and cobimetinib in braf-mutated melanoma. N Engl J Med. 2014;371:1867-76.
57 Robert C, Karaszewska B, Schachter J, Rutkowski P, Mackiewicz A, Stroiakovski D, et al. Improved overall survival in melanoma with combined dabrafenib and trametinib. N Engl J Med. 2015;372:30-9.

58 Dummer R, Goldinger SM, Turtschi CP, Eggmann NB, Michielin O, Mitchell L, et al. Vemurafenib in patients with braf(v600) mutationpositive melanoma with symptomatic brain metastases: Final results of an open-label pilot study. Eur J Cancer. 2014;50:611-21.

59 Falchook GS, Long GV, Kurzrock R, Kim KB, Arkenau TH, Brown $\mathrm{MP}$, et al. Dabrafenib in patients with melanoma, untreated brain metastases, and other solid tumours: A phase 1 dose-escalation trial. Lancet. 2012;379:1893-901.

60 Ascierto PA, Schadendorf D, Berking C, Agarwala SS, van Herpen CM, Queirolo P, et al. Mek162 for patients with advanced melanoma harbouring nras or val600 braf mutations: A non-randomised, open-label phase 2 study. Lancet Oncol. 2013;14:249-56.

61 Hodi FS, Corless CL, Giobbie-Hurder A, Fletcher JA, Zhu M, MarinoEnriquez A, et al. Imatinib for melanomas harboring mutationally activated or amplified kit arising on mucosal, acral, and chronically sundamaged skin. J Clin Oncol. 2013;31:3182-90.

62 Legha SS, Ring S, Papadopoulos N, Plager C, Chawla S, Benjamin R. A prospective evaluation of a triple-drug regimen containing cisplatin, vinblastine, and dacarbazine (cvd) for metastatic melanoma. Cancer. 1989;64:2024-9.

63 Hauschild A, Agarwala SS, Trefzer U, Hogg D, Robert C, Hersey P, et al. Results of a phase iii, randomized, placebo-controlled study of sorafenib in combination with carboplatin and paclitaxel as second-line treatment in patients with unresectable stage iii or stage iv melanoma. J Clin Oncol. 2009;27:2823-30.

64 Hamm C, Verma S, Petrella T, Bak K, Charette M. Biochemotherapy for the treatment of metastatic malignant melanoma: A systematic review. Cancer Treat Rev. 2008;34:145-56.

65 Ives NJ, Stowe RL, Lorigan P, Wheatley K. Chemotherapy compared with biochemotherapy for the treatment of metastatic melanoma: A meta-analysis of 18 trials involving 2,621 patients. J Clin Oncol. 2007;25:5426-34.

66 O'Day S, Kim JA, Sosman AC, Petersion S, Feng DR, Minor JP, et al. A randomized phase ii study evaluating the activity of bevacizumab in combination with carboplatin plus paclitaxel in patients with previously untrated advanced melanoma. Eur J Cancer Supp. 2009;7:Abstract 23LBA.

67 von Moos R, Seifert B, Simcock M, Goldinger SM, Gillessen S, Ochsenbein A, et al. First-line temozolomide combined with bevacizumab in metastatic melanoma: A multicentre phase ii trial (sakk 50/07). Ann Oncol. 2011;23:531-6.

68 Saiag P, Bosquet L, Guillot B, Verola O, Avril MF, Bailly C, et al. Management of adult patients with cutaneous melanoma without distant metastasis. 2005 update of the french standards, options and recommendations guidelines. Summary report. Eur J Dermatol. 2007;17:325-31.

69 Francken AB, Bastiaannet E, Hoekstra HJ. Follow-up in patients with localised primary cutaneous melanoma. Lancet Oncol. 2005;6:608-21.

70 Garbe C, Schadendorf D, Stolz W, Volkenandt M, Reinhold U, Kortmann RD, et al. Short german guidelines: Malignant melanoma. J Dtsch Dermatol Ges. 2008;6(Suppl 1):S9-S14.

71 Bastiaannet E, Wobbes T, Hoekstra OS, van der Jagt EJ, Brouwers AH, Koelemij R, et al. Prospective comparison of [18f]fluorodeoxyglucose positron emission tomography and computed tomography in patients with melanoma with palpable lymph node metastases: Diagnostic accuracy and impact on treatment. J Clin Oncol. 2009;27:4774-80.

72 Beyeler M, Waldispuhl S, Strobel K, Joller-Jemelka HI, Burg G, Dummer R. Detection of melanoma relapse: First comparative analysis on imaging techniques versus $\mathrm{s} 100$ protein. Dermatology. 2006;213:187-91.

73 Kruijff S, Bastiaannet E, Kobold AC, van Ginkel RJ, Suurmeijer AJ, Hoekstra HJ. S-100b concentrations predict disease-free survival in stage iii melanoma patients. Ann Surg Oncol. 2009;16:3455-62. 